\title{
DE ZACARIAS AOS DIAS DE HOJE, A SEGURANÇA PÚBLICA EM CURITIBA
}

\author{
Alex Ferreira Garcia
}

Pensando sobre como era antes e como é hoje, partimos de um pequeno exercício mental, pensar segurança pública nos dias atuais, e analisar como esta era no princípio do pensar segurança pública no Estado do Paraná, será que esta mudou?

Para balizar nosso pensar, adotamos um método, denominado hipotético-dedutivo de Popper $^{1}$, pois nos deparamos com um problema, a criminalidade, e queremos ver como está uma das soluções de nosso problema, a segurança pública. Colocamos como uma solução, pois podemos encontrar outras soluções, como a conscientização da população perante a educação, investimentos em melhorias sociais, entre outros.

O problema da criminalidade nos chama a atenção todos os dias, como no dia 01 de Dezembro de 2008, com a reportagem do jornal Paraná-online com seguinte manchete: "Grande Curitiba registra 24 homicídios em três dias", ou ainda podemos utilizar a reportagem do dia 28 de Novembro de 2008, com a manchete: "Crimes na CIC e Vila Hauer", entre tantas outras reportagens que trazem quase que diariamente a notícia de crimes. ${ }^{2}$

Assim, levantamos o problema frente à distribuição do policiamento na cidade de Curitiba, pois sabemos que existe uma quantidade de policiais que trabalham para propiciar a segurança pública, porém, quantos são e onde estão? E o número deste é

${ }^{1}$ POPPER, K. A lógica da Investigação Cientifica. São Paulo: Abril Cultural,1980.

2 Grande Curitiba Registra 24 homicídios. Paraná-Online. Disponível em: http://www.parana-online.com.br/editoria/policia/news/339184/; Crimes na CIC e no Hauer. Paraná-Online. Disponível em: http://www.paranaonline.com.br/editoria/policia/news/338669/. 
suficiente para propiciar segurança ao cidadão em todo território urbano de Curitiba?

Temos assim nosso norte para orientar nossa pesquisa, mas de onde começaríamos a pesquisar? Como estamos analisando a segurança pública em Curitiba, começamos analisando com a criação desta, no ano de 1854, relativizando frente à população da época, para com estes dados, poder comparar o século XIX com o XXI.

Para entender melhor nosso objeto de estudo, realizamos pesquisa bibliográfica, em estudo sobre criminalidade e distribuição da segurança pública, assim como também quais as responsabilidades de propiciar segurança no município de Curitiba, baseando-nos na lei para tal.

Para explanar sobre a nossa fundamentação teórica, iniciamos a respeito do método escolhido para realizar esta pesquisa, sendo ele o método hipotético-dedutivo, este como embasamento histórico. ${ }^{3}$

O método hipotético-dedutivo foi definido por Popper (Sir Karl Raymund Popper) a partir de criticas à indução. A indução, para Popper, não se justifica, pois o salto indutivo do particular ("alguns") para o geral ("todos") exigiria que a observação de fatos isolados atingisse o infinito, o que dificilmente poderia ocorrer, por maior que fosse a quantidade de fatos observados. Outra argumentação utilizada por Popper é o de que a indução cai invariavelmente no apriorismo. A indução parte de uma coerência metodológica porque é justificada dedutivamente. Sua justificação indutiva exigiria o trabalho de sua verificação factual. Isso significaria cair numa petição de princípio, ou seja, apoiar-se numa demonstração sobre a tese que se pretende demonstrar. ${ }^{4}$

Já para o método hipotético-dedutivo, quando os conhecimentos disponíveis sobre determinado assunto são insuficientes para a explicação de um fenômeno, surge o problema.

\footnotetext{
${ }^{3}$ POPPER, K. Op. cit.

4 LAKATOS, Eva Maria; MARCONI, Marina de Andrade. Fundamentos de metodologia científica. $3^{\text {a }}$ ed. São Paulo: Atlas, 1991.
} 
Assim, posteriormente ao se deparar com o problema, são formuladas conjecturas ou hipóteses. Perante as hipóteses formuladas, deduzemse conseqüências que deverão ser testadas ou falseadas. Sendo que falsear significa tentar tornar falsas as conseqüências deduzidas das hipóteses, procurando evidências empíricas para derrubá-la e quando não se consegue demonstrar qualquer caso concreto capaz de falsear a hipótese, tem-se a sua corroboração, que não excede o nível do provisório. ${ }^{5}$

De acordo com os estudos de Popper, a hipótese mostra-se válida ao superar todos os testes, mas não definitivamente confirmada, já que a qualquer momento poderá surgir um fato que a invalide. $^{6}$

Este método, hipotético-dedutivo, possui boa aceitação e empregabilidade entre as ciências naturais, sendo considerado como um dos únicos métodos rigorosamente lógico. Nas ciências sociais, entretanto, a utilização desse método mostra-se bastante difícil, pois nem sempre podem ser deduzidas conseqüências observadas das hipóteses. Já que ações sociais envolvem agentes políticos e diversos fatores que não podem ser falseados como um todo, ou mesmo, medidos exatamente e empregados, podendo surgir um fato que o invalide no mesmo momento que ele foi empregado. Assim, devemos estudar exaustivamente todas as probabilidades, não sendo possíveis por integral neste trabalho, sendo somente um breve estudo, que tem como meta, colaborar nas tomadas de decisões frente à segurança pública na cidade de Curitiba, no Estado do Paraná.

Focamos a vertente histórica na utilização do método hipotético-dedutivo para melhor compreender a conjuntura atual, para com este, poder elaborar algumas hipóteses de solução, levando em conta que este é um simples estudo que demandou um determinado tempo e empenho para ser feito, sendo que para melhor fazê-lo, deveríamos empregar mais tempo e recursos, algo que não dispúnhamos atualmente, podendo ser feito em outra ocasião.

\footnotetext{
${ }^{5}$ Ibidem.

${ }^{6}$ Ibidem.
} 
O tema segurança pública tem como abordagem inicial no Estado do Paraná, com seu primeiro governador, sendo este ainda governador da província recém desmembrada da província do Estado de São Paulo, quando em seu primeiro relatório, datado de 1854, coloca:

A segurança individual, se não he qual convem e deseja-se, pode-se affirmar que he superior ao que permittem os escassos recursos, que na actualidade estão á disposição da polícia, e com que provavelmente por algum tempo ainda se há de contar na província. ${ }^{7}$

Zacarias ainda falava da tranqüilidade com que estava a província e a cidade de Curitiba nesta ocasião: "No espaço de tempo decorrido desde 19 de dezembro, dia da instalação da província até o presente, nenhum acontecimento houve, que abalasse, mesmo de leve, o socego público". ${ }^{8}$

Balizamo-nos por essa época, meados do século XIX, para com dados do período atual, início do século XXI, fazer uma análise comparativa, utilizando o método de Popper (1980) denominada método hipotético-dedutivo, com base histórica.

Para tal, colocamos os dados que Zacarias de Góes e Vasconcellos, presentes estes em seu relatório, o Relatório do presidente da província do Paraná, utilizado anteriormente e que aproveitamos para ressaltar este trecho do relatório:

Chamando agora a vossa attenção sobre a força, que cumprevos fixar, direi, que, em attenção aos tênues recursos da província, basta que, por ora, autoriseis, desde já, a creação de huma companhia de 67 praças pela forma constante do plano annexo á este relatório sob n.5.

\footnotetext{
${ }^{7}$ VASCONCELLOS, Zacarias de Góes e. Relatório do presidente da província do Paraná, o conselheiro Zacarias de Góes e Vasconcellos, na abertura da Assemblea Legislativa Provincial em 15 de julho de 1854. Curityba, Typ. Paranaense de Candido Martins Lopes, 1854. p. 3. Disponível em: http://brazil.crl.edu/bsd/bsd/614/index.html.
}

${ }^{8}$ Ibidem, p. 2. 
Proponho nelle huma secção de cavallaria, porque esperar que sejão em certos casos, coroados de feliz resultado diligenciais policiaes confiadas á soldados de pé contra indivíduos ás vezes bem montados, como he costume por esses campos, parece querer o impossível. ${ }^{9}$

Trecho este que cria a Polícia Militar do Paraná, que será composta, conforme relatório apontado por este (relatório sob n.5), por um capitão, um tenente, um alferes, um $1^{\mathrm{o}}$ sargento, dois $2^{\mathrm{o}}$ Sargento, um Furriel, oito cabos, dois cornetas e cinqüenta soldados, totalizando sessenta e sete membros.

Focamos desde de início a instituição da Polícia Militar do Paraná, pois esta perante a constituição, é a única que pode propiciar segurança pública, frente a ordem pública, conforme artigo 144 da constituição nacional que diz: " $\$ 5^{\circ}$ - às polícias militares cabem a polícia ostensiva e a preservação da ordem pública”.

Assim, fomos além de somente colocar números sobre a quantidade de agentes de segurança, adentrando na responsabilidade perante a lei maior da nação, a constituição de 1988, e embasamento empírico frente a estudos realizados por diversos estudiosos, entre eles Emilio Durkheim e Michel Foucault, assim como outros contemporâneos atuais que realizaram pesquisas frente a segurança pública e que consideramos de importância para a análise. Não questionando estratégias da corporação Polícia Militar do Paraná, e sim, a quantidade de agentes que compõem seu quadro efetivo para cumprir a lei maior da nação, a constituição de 1988, quanto ao dever de preservação da ordem pública e o policiamento ostensivo propiciando segurança ao cidadão, sendo a segurança obrigação do Estado, conforme a própria constituição deste.

Em nossa pesquisa, realizamos levantamento de informações a respeito da responsabilidade legal das instituições que temos para propiciar a segurança pública, sendo estas na esfera federal, estadual e municipal. Levantamento que tem por base a lei maior da nação brasileira, a constituição, no nosso caso atual, a Constituição de 1988,

${ }^{9}$ VASCONCELLOS, Zacarias de Góes e. Op. cit. p. 32. 
com a atualização das Emendas Constitucional realizada em de 1998. Assim com dados atuais e históricos da composição quantitativa das instituições de segurança pública em Curitiba. Temos que ressaltar que focamos somente a segurança na área urbana do município de Curitiba, pois se colocássemos o município como um todo, teríamos que abordar todas suas rodovias, tanto estaduais (de responsabilidade da polícia rodoviária estadual) e as federais (de responsabilidade da polícia rodoviária federal), e sua malha férrea (de responsabilidade da polícia ferroviária federal), conforme constatado e apontado no decorrer deste trabalho.

Partimos do princípio para analisar a segurança:

O Valor do indivíduo depende do lugar em que está e que, desse modo, a igualdade dos cidadãos supõe, para todos, uma acessibilidade semelhante aos bens e serviços, sem os quais a vida não será vivida com aquele mínimo de dignidade que se impõe. Isso significa, em outras palavras, um arranjo territorial desses bens e serviços de que conforme a sua hierarquia, os lugares sejam pontos de apoio, levando em conta a densidade demográfica e econômica da área e sua fluidez. ${ }^{10}$

Pretendemos realizar uma repartição espacial não mercantil dos bens e serviços (no nosso caso o serviço segurança pública e sua distribuição), baseado somente no interesse público, para trazer bemestar para uma grande quantidade de cidadãos e servir como alavanca para novas atividades. Onde o emprego aumentando e a massa salarial acrescida representaria uma base para a criação de novas atividades, que, por sua vez, atrairiam outras mais. ${ }^{11}$

Baseamo-nos em uma dissertação a respeito do custo da criminalidade em Curitiba, realizada por Evandro Camargos Teixeira, denominada: Estimando o impacto econômico da violência: custos da

10 SANTOS, Milton. O Espaço do Cidadão. 7 ed. São Paulo: Editora da Universidade de São Paulo, 2007. p. 144.

${ }^{11}$ Ibidem. 
criminalidade em Curitiba, para com esta ressaltar o quanto o crime afeta economicamente uma cidade e seus cidadãos. ${ }^{12}$

Após coleta de dados e análise desses, confeccionamos alguns mapas e gráficos para melhor entendimento e visualização dos dados.

Realizamos uma espacialização da Segurança Pública no município de Curitiba, perante as esferas estadual e municipal, fazendo um paralelo histórico, com a criação das instituições que prestam os serviços de segurança pública e as atuais circunstâncias que se encontram estas. Tivemos como balizador o ano vigente de 2008 para analisar a segurança pública na cidade de Curitiba no estado do Paraná.

Investigamos os mecanismos de segurança promovida pelo Estado, juntamente com o funcionamento e comprometimento destes frente à esfera pública, suas bases legais e os efetivos para cumprir o quesito segurança ao cidadão. Averiguando como está a disposição espacial da segurança no município de Curitiba e como a mesma é propiciada pelo Estado para seus cidadãos. Posteriormente, fizemos uma análise pautada na abordagem da metodologia, colocando em pauta o que vem a ser a necessidade de utilização de um método para fazer ciência, citando LaKatos e Marconi, que dizem:

Todas as ciências caracterizam-se pela utilização de métodos científicos; em contrapartida, nem todos os ramos de estudo que empregam estes métodos são ciências. Dessas afirmações podemos concluir que a utilização de métodos científicos não é da alçada exclusiva da ciência, mas não há ciência sem o emprego de métodos científicos. ${ }^{13}$

Posteriormente, escolhemos, após pesquisa prévia, utilizarmo-nos do método hipotético-dedutivo, juntamente com SIG

12 TEIXEIRA, Evandro Camargos. Estimando o impacto econômico da violência: custos da criminalidade em Curitiba. Dissertação (mestrado) - Programa de PósGraduação em Desenvolvimento Econômico, UFPR. Curitiba, 2005.

${ }^{13}$ LAKATOS, Eva Maria; MARCONI, Marina de Andrade. Op. cit. 
(Sistema de Informação Geográfica) para analisar o espaço frente à segurança pública.

Temos que ressaltar que este trabalho é somente uma hipótese, sendo empregado neste apenas uma reflexão frente a números, pois realizamos um paralelo da população do referido município quanto à criação do mecanismo de segurança pública na época (1854), o contingente dos funcionários desde mecanismo daquela ocasião, fazendo uma extrapolação do que deveríamos ter hoje para ser igualado, proporcionalmente, a meados do século XIX.

Realizamos também, uma simples abordagem do que é crime, mas sem a pretensão de estudar o referido tema, que foi abordado em diferentes focos (econômico, social, político, entre outros) e como a simples bagagem da especialização não nos permite realizar um destes focos mais a fundo, comprometendo um tempo de estudo e pesquisa somente sobre um dos focos do referido tema, sendo inviável nesta simplória monografia e além de nossas capacidades acadêmicas do até então.

O ser humano realiza suas ações em um determinado espaço, sendo consideradas estas ações realizadas em sociedade como fatos sociais, assim apontados por Emilio Durkheim. ${ }^{14}$ Assim, definimos crime com sendo toda ação contrária aos costumes, à moral e à lei, que é legalmente punida, ou que é reprovada pela consciência. Conforme Durkheim, o crime não se observa apenas na maior parte das sociedades desta ou daquela espécie, mas em todas as sociedades. Não há nenhuma onde não exista criminalidade. Colocar o crime como uma doença social seria admitir que a doença não é algo acidental, mas, ao contrário, "deriva em certos casos, da constituição fundamental do ser vivo...", sendo assim, "o crime não deve mais ser

\footnotetext{
${ }^{14}$ Apud TEIXEIRA, Ricardo Rodrigues. Três fórmulas para compreender "O suicídio" de Durkheim. Disponível em http://www.interface.org.br/revista11/espaco1.pdf.
} 
concebido como um mal que não possa ser contido dentro de limites demasiado estreitos". ${ }^{15}$

A criminalidade é um fato que afeta todos os cidadãos em todo mundo, sendo na América Latina mais intensa e um problema ao desenvolvimento econômico. No Brasil, a criminalidade é como uma doença, segundo Evandro Camargos Teixeira, não tendo como delinear um fator preponderante, mas o crescimento exponencial da população, o processo de urbanização, ineficiência do código penal, o comércio clandestino de armas, o "descalabro" penitenciário, são alguns fatores, entre outros, apontados como causas estruturais da proliferação da violência no país. ${ }^{16}$

Os governos mobilizam recursos para combater o crime e os cidadãos também investem em segurança, sendo este custo social um redutor da eficiência do setor legal da economia, desviando também agentes para a atividade econômica ilegal, sendo que estes recursos poderiam ser empregados em outros setores, como educação e saúde, juntamente com o desenvolvimento econômico. Destacamos também que este custo social é uma forma de medição da perda do bem-estar imposta pelo crime violento, sendo a mensuração dos custos da criminalidade uma abordagem com destaque na Ciência Econômica que analisa o crime e seus impactos sobre a atividade econômica ("economia da criminalidade"). Teixeira estima em sua dissertação de mestrado os custos da criminalidade e o impacto econômico da violência sobre o bem-estar social em Curitiba, metrópole com criminalidade considerada intermediária em comparação com as outras capitais, porém com avanços nas últimas décadas.

Ainda segundo Teixeira, "a segurança não pode ser considerada um bem público", pois temos a sua terceirização,

${ }^{15}$ CORRÊA, Sérgio Luís de Castro Mendes. O Conceito de Crime em Durkheim. Disponível em http://www.escola.agu.gov.br/revista/Ano_VI_fevereiro_2006/conceito\%20de\%20c rime.pdf.

${ }^{16}$ TEIXEIRA, Evandro Camargos. Op. cit.

${ }^{17}$ Idem. 
contrariando o direito universal de todos seres humanos, sendo a segurança considerada da alça de provimentos do Estado a todos seus cidadãos de forma gratuita e com qualidade. Podemos notar este ao ver a proporção de gastos em segurança do setor privado em relação aos gastos públicos, refletindo a ineficiência do Estado em prover segurança, pois o cidadão além de pagar impostos e taxas, vê-se obrigado a realizar gastos com segurança privada. ${ }^{18}$

Partimos do princípio de que o crime já é mapeado constantemente em Curitiba, frente o Projeto Mapa do Crime Planejamento e Segurança, explanado este pelo excelentíssimo senhor Luiz Fernando Ferreira Delazari, Secretário de Estado da Segurança Pública do Paraná, em São Paulo. ${ }^{19}$

No caso da nossa pesquisa, pesquisamos para conhecer melhor o espaço delimitado por nós, no caso o município de Curitiba e seus bairros, no estado do Paraná colocando frente a este a presença do Estado Governo, que tem a obrigação perante a lei maior que rege este país, que é a Constituição Federal de 1988, de fornecer segurança ao cidadão. Consta no Preâmbulo da Constituição Federal que:

(...) Estado Democrático, destinado a assegurar o exercício dos direitos sociais e individuais, a liberdade, a segurança, o bem-estar, o desenvolvimento, a igualdade e a justiça como valores supremos de uma sociedade fraterna, pluralista e sem preconceitos, fundada na harmonia social e comprometida, na ordem interna e internacional, com a solução pacífica das controvérsias, promulgamos, sob a proteção de Deus, a

${ }^{18}$ TEIXEIRA, Evandro Camargos. Op. cit..

19 DELAZARI, Luiz Fernando Ferreira. Projeto Mapa do Crime - Planejamento e Segurança. Secretário de Estado da Segurança Pública do Paraná. São Paulo, 17 De Julho De 2008. Disponível em http://www.geobr.com.br/conteudo/arquivos/Congresso\%20EXPO\%20GPS/Sala\% 206/Geotecnologias $\% 20$ combatendo $\% 200 \% 20$ crime $\% 20$ \%20Luis\%20Fernando\%20Delazari.ppt 
seguinte CONSTITUIÇÃO DA REPÚBLICA FEDERATIVA DO BRASIL. $^{20}$

Podemos esmiuçar melhor citando o Art. 144, que diz: "A segurança pública, dever do Estado, direito e responsabilidade de todos, é exercida para a preservação da ordem pública e da incolumidade das pessoas e do patrimônio".

Nossa pesquisa foi pautada no quesito segurança, para constatar se há a devida empregabilidade dos mecanismos do Estado para prover a requerida segurança que é abordada em sua lei maior, sendo abordado inicialmente este tema no título II, capítulo II, artigo sexto, pois nele está escrito que: "São direitos sociais a educação, a saúde, o trabalho, a moradia, o lazer, a segurança, a previdência social, a proteção à maternidade e à infância, a assistência aos desamparados, na forma desta Constituição". 21

Temos que ressaltar que o município aparentemente é uma esfera do Poder Público isenta de responsabilidades judiciárias e policiais na esfera dos crimes contra a pessoa e o patrimônio, podendo apenas contribuir com um policiamento complementar de Parques e Jardins e instalações do próprio Município. ${ }^{22}$

Entendemos que este procurou verificar se estava havendo cumprimento da lei maior de nossa nação, tornando esta palpável frente à espacialização do segurança prestada pelo Estado, quantificando esta, sendo de um modelo hipotético com base histórica, não analisaremos com base qualitativa, pois sabemos que a

20 Constituição da República Federativa do Brasil: Texto constitucional promulgado em 5 de outubro de 1988, com as alterações adotadas pelas Emendas Constitucionais $n^{\circ}$ s 1/92 a 56/2007 e pelas Emendas Constitucionais de Revisão n ${ }^{\circ} \mathrm{s}$ 1 a 6/94. Brasília: Senado Federal. Disponível em http://www.planalto.gov.br/ccivil_03/Constituicao/Constitui\%C3\%A7ao.htm

${ }^{21}$ Constituição da República Federativa do Brasil... Op. cit.

${ }^{22}$ GOMES, Carlos Alberto da Costa. Espaço Urbano e Criminalidade: Uma Breve Visão do Problema. Revista de Desenvolvimento Econômico, Salvador, v. 8, n. 1, 2005. 
corporação da polícia militar sempre atua muito bem em suas funções e tem nosso respeito por tal, porém sabemos que a quantidade influi na prestação de serviços.

Espacializar ou mesmo localizar-se no espaço é uma área científica de abordagem feita pela Geografia. Utilizando-nos deste conhecimento desta ciência, pretendemos pensar o ato de organizar melhor o espaço, otimizando o mesmo pra proporcionar melhor qualidade de vida para o ser humano que neste vive. Pensamos assim em dividir o espaço para melhor entendê-lo, partindo de pressupostos desenvolvidos por Vidal de La Blache, denominado "Regionalização".

Assim, existem pensadores que se utilizam de La Blache para realizar seus estudos e contribuir para pensar ciência. Temos assim a seguinte citação realizada por Ribeiro:

(...) qualquer paisagem está organizada e é a trama das regiões, concebidas como áreas de extensão de determinada paisagem, que constitui o objetivo último das investigações devidamente conduzidas pelos Geógrafos. Seria desejável que eles pudessem aplicar este método por toda a parte e insuflar o espírito da sua ciência nos projetos de divisão regional, ditos de regionalização e de organização humana do espaço. $^{23}$

Utilizando-nos deste pensar, pensamos região como prédeterminada por delimitações políticas, no nosso caso, o município de Curitiba e seus bairros, já que bairro perante o IBGE é a menor unidade administrativa e a organização humana do espaço com o intuito de propiciar segurança para estes que deste espaço se utilizam. $^{24}$ Tendo como propiciador desta segurança o Estado, ou seja, segurança pública. Tentando assim, aplicar este método neste contexto e contribuindo para o desenvolvimento científico frente a

${ }^{23}$ RIBEIRO, Orlando. Paisagens, Regiões e Organização do Espaço. Finisterra, XXXVI,72, 2001.

${ }^{24}$ IBGE, Instituto Brasileiro de Geografia e Estatística. Censo 2000. Disponível em: http://www.ibge.gov.br/home/ 
aplicação metodológica do regionalizar e gerir o espaço. Temos ainda que ressaltar que "o ordenamento do território é cada vez mais entendido, tanto ao nível técnico como político, como uma questão fundamental que se encontra fortemente relacionada como praticamente todas as políticas". ${ }^{25}$ Para tal, a administração pública estatal dividiu a cidade de Curitiba em três batalhões para melhor administração e controle, sendo estes, o $12^{\circ}$ Batalhão, $13^{\circ}$ Batalhão e o $20^{\circ}$ Batalhão, havendo outros batalhões como o Batalhão de Policiamento de Trânsito - BPTran que é uma Unidade Especializada no policiamento de trânsito de Curitiba, subordinado ao Comando do Policiamento da Capital da Polícia Militar do Paraná, entre outros, sendo estes específicos para determinados atendimentos, no caso deste citado, trânsito. Mas nos limitaremos em analisar frente ao policiamento de polícia ostensiva e a preservação da ordem pública (como consta nas suas atribuições frente à constituição), realizado pelo efetivo dos batalhões de área, sendo nesta pesquisa os três citados anteriormente.

A segurança pública está prevista em lei como sendo composta pelos seguintes órgãos: polícia federal; polícia rodoviária federal; polícia ferroviária federal; polícias civis; polícias militares e corpos de bombeiros militares, conforme o artigo 144 da constituição federal. Devendo ser esta, "dever do Estado, direito e responsabilidade de todos", como dito anteriormente. ${ }^{26}$

As competências das referidas instituições que devem prover a segurança pública estão previstas no mesmo artigo que lista estas como sendo as responsáveis pela segurança pública frente ao papel do estado sendo estas responsabilidades, conforme o artigo 144 da constituição federal de 1988:

${ }^{25}$ QUENTAL, Nunes. A organização espacial do território como contributo para a sustentabilidade. 2008.

Disponível

em http://conferencias.iscte.pt/viewpaper.php?id=58\&cf=3.

${ }^{26}$ Constituição da República Federativa do Brasil... Op. cit. 
$\S 1^{\circ}$ A polícia federal, instituída por lei como órgão permanente, organizado e mantido pela União e estruturado em carreira, destina-se a:(Redação dada pela Emenda Constitucional nº 19, de 1998)

I - apurar infrações penais contra a ordem política e social ou em detrimento de bens, serviços e interesses da União ou de suas entidades autárquicas e empresas públicas, assim como outras infrações cuja prática tenha repercussão interestadual ou internacional e exija repressão uniforme, segundo se dispuser em lei;

II - prevenir e reprimir o tráfico ilícito de entorpecentes e drogas afins, o contrabando e o descaminho, sem prejuízo da ação fazendária e de outros órgãos públicos nas respectivas áreas de competência;

III - exercer as funções de polícia marítima, aeroportuária e de fronteiras; (Redação dada pela Emenda Constitucional nº 19, de 1998)

IV - exercer, com exclusividade, as funções de polícia judiciária da União.

$\S 2^{\circ}$ A polícia rodoviária federal, órgão permanente, organizado e mantido pela União e estruturado em carreira, destina-se, na forma da lei, ao patrulhamento ostensivo das rodovias federais.(Redação dada pela Emenda Constitucional $\mathrm{n}^{\circ} 19$, de 1998)

$\S 3^{\circ}$ A polícia ferroviária federal, órgão permanente, organizado e mantido pela União e estruturado em carreira, destina-se, na forma da lei, ao patrulhamento ostensivo das ferrovias federais. (Redação dada pela Emenda Constitucional $n^{\circ} 19$, de 1998)

$\S 4^{\circ}$ - às polícias civis, dirigidas por delegados de polícia de carreira, incumbem, ressalvada a competência da União, as funções de polícia judiciária e a apuração de infrações penais, exceto as militares.

$\S 5^{\circ}$ - às polícias militares cabem a polícia ostensiva e a preservação da ordem pública; aos corpos de bombeiros militares, além das atribuições definidas em lei, incumbe a execução de atividades de defesa civil. 
$\S 6^{\circ}$ - As polícias militares e corpos de bombeiros militares, forças auxiliares e reserva do Exército, subordinam-se, juntamente com as polícias civis, aos Governadores dos Estados, do Distrito Federal e dos Territórios.

$\S 7^{\circ}$ - A lei disciplinará a organização e o funcionamento dos órgãos responsáveis pela segurança pública, de maneira a garantir a eficiência de suas atividades.

$\S 8^{\circ}$ - Os Municípios poderão constituir guardas municipais destinadas à proteção de seus bens, serviços e instalações, conforme dispuser a lei.

$\S 9^{\circ}$ A remuneração dos servidores policiais integrantes dos órgãos relacionados neste artigo será fixada na forma do $\S 4^{\circ}$ do art. 39. (Incluído pela Emenda Constitucional nº 19, de 1998)

Ressaltamos assim as funções da Polícia Civil, que é a "polícia judiciária e a apuração de infrações penais, exceto as militares". E a polícia militar tem as funções de "a polícia ostensiva e a preservação da ordem pública", ou seja, evitar os crimes perante policiamento e propiciar segurança ao cidadão.

Para Foucault, "a disciplina procede em primeiro lugar à distribuição dos indivíduos no espaço. Para isso, utiliza diversas técnicas", não vem ao caso deste trabalho saber onde exatamente está cada policial, e sim a região de atuação destes e quantos são, pois a logística de onde colocar cada agente de segurança é uma área já estudada e aplicada diariamente pelos tomadores de decisões das instituições de segurança pública, levando em conta eventos e estratégias de combate ao crime. ${ }^{27}$

Como delimitamos nossa área de estudo como sendo o município de Curitiba, foi feita uma relação quantitativa da população e os agentes de segurança pública, partindo com uma reflexão histórica, desde as criações das referidas instituições, seus efetivos

${ }^{27}$ FOUCAULT, Michel. Vigiar e Punir: História da Violência nas Prisões. Rio de Janeiro, Editor Vozes, 1975. 
iniciais e a quantidade populacional nas referidas datas de criação, fazendo um paralelo com os dias atuais.

Como ponto comparativo, temos assim que realizar a explanação da história das referidas instituições envolvidas diretamente nesta pesquisa.

A Polícia Militar do Paraná foi criada em 10 de Agosto de 1854, como Companhia da Força Policial, pelo presidente da nova Província, Zacarias de Góes e Vasconcelos, tendo nomeado o Capitão de $1^{\text {a }}$ Linha do Exército Imperial, Joaquim José Moreira Mendonça, para organizar a Corporação, que na atual circunstância era composta

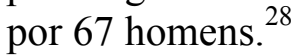

Segundo Carlos Alberto da Costa Gomes ${ }^{29}$, o município não tem obrigação de propiciar segurança, porém, em Curitiba há a integração das polícias e guarda municipal, no sistema denominado CIOSP (Centros Integrados de Operações de Segurança Pública), sendo realizado atendimento ao cidadão também pela guarda municipal. Portanto, incluiremos a guarda municipal em nossos estudos, porém, esta ainda não pode ser integrada como um todo, pois algumas atuações a guarda não pode realizar, ficando somente a cargo da polícia militar e civil.

A guarda municipal tem sua criação em 17 de julho de 1986, perante a lei municipal, sendo esta a Lei Ordinária $n^{0}$ $6867 / 1986$, de iniciativa de José Maria Correia, como projeto $n^{0}$ 56/1984. A Guarda Municipal não recebeu inicialmente esta denominação, tendo como nome inicial: Serviço Municipal de Vigilância - VIGISERV. (SPL, 2007). Posterior à Constituição de 1988, este Serviço Municipal de Vigilância passa a se chamar de Guarda Municipal de Curitiba, perante a Lei Municipal n 7356 de 1989 (SPL, 2008). Não havendo modificação na função do VIGISERV, e sim somente na denominação deste para Guarda Municipal, mantendo todas as atribuições que consta na lei de criação

28 POLÍCIA MILITAR DO PARANÁ. HISTÓRICO. Disponível em http://www.pm.pr.gov.br/modules/conteudo/conteudo.php?conteudo=1

${ }^{29}$ GOMES, Carlos Alberto da Costa. Op. cit. 
desta, que já comentamos anteriormente. Porém, temos que ressaltar as atribuições, sendo a primeira atribuição a de "exercer a vigilância interna e externa sobre os próprios municipais, parques, jardins, escolas, teatros, museus, bibliotecas, cemitérios, mercados, feiraslivres, no sentido de: a) protegê-los dos crimes contra o patrimônio" (SPL, 2008).

Infelizmente não poderemos colocar o efetivo da guarda municipal, que é atualmente de 1.695 (SPL, 2007) e mais duzentos em formação, tendo um total de 1.895 agentes, em nossos estudos, pois, conforme a atribuição legal da constituição, já colocado anteriormente, "os Municípios poderão constituir guardas municipais destinadas à proteção de seus bens, serviços e instalações, conforme dispuser a lei”, não cabendo a estes o policiamento de polícia ostensiva e a preservação da ordem pública. Mas, como delimitamos o ano de 2008 e modificações podem ocorrer na constituição, quem sabe nos próximos estudos com este tema já incorporem estes.

Continuamos nossa análise com a história da polícia civil, utilizando-nos da pesquisa de STRAUBE (2008) que está disponível no site da polícia civil do Paraná. A história da polícia civil começou com o rei de Portugal D. José I que cria em 1760, o cargo de Intendente Geral de Polícia da Corte e do Reino, com amplos poderes e ilimitada jurisdição, estendendo-se, portanto, ao Brasil, com o objetivo de garantir a ordem, a segurança e a paz públicas. Nas vilas haviam os Delegados e Subdelegados do Intendente, como seu representante, sendo estas as primeiras evidências da polícia civil.

No princípio as atividades jurídicas confundiam-se com as policiais. Por Decreto Imperial, é nomeado o primeiro Chefe de Polícia do Paraná, o Bacharel Antonio Manoel Fernandes Júnior que veio do Rio de Janeiro, vindo juntamente com o Primeiro presidente da nova província, Zacarias de Goes e Vasconcelos. ${ }^{30}$

No dia 22 de novembro de 1871, via Decreto Imperial $n^{\circ}$ 4824, foi instituído o inquérito policial. Já em 17 de junho de 1911,

\footnotetext{
${ }^{30}$ STRAUBE, Ernani Costa. "Histórico" da polícia civil do Paraná. Disponível em http://www.policiacivil.pr.gov.br/modules/conteudo/conteudo.php?conteudo=1.
} 
pelo Decreto $\mathrm{n}^{\circ} 262$, foi criada a Guarda Civil do Paraná, órgão civil, incumbido de auxiliar na manutenção da ordem e segurança públicas, e teve honrosa atuação, sendo considerada corporação de elite da Polícia Civil. $^{31}$

Em 1918 é publicada a obra "O Agente Policial", de Antonio Francisco Nauffal sendo uma das primeiras manifestações sobre o desempenho, a utilidade e os meios necessários para a missão policial, enriquecida com a divulgação de técnicas de polícia científica (na época era considerado heresia o uso destas técnicas). Sendo raríssima hoje em dia esta obra que foi publicada pela Tipografia da Penitenciária do Estado e republicada no volume 6 (1978) da Revista da Polícia Civil do Paraná. ${ }^{32}$

Somente no ano de 1922, perante a Lei ${ }^{0} 3052$ é criada a polícia de carreira. E com a Emenda Constitucional $n^{\circ} 03$ de 1971 fixou a organização da Polícia Civil com carreiras funcionais, criou o Conselho da Polícia Civil e determinou o provimento da carreira de Delegado de Polícia por Bacharel em Direito, aprovado em concurso público. O primeiro Estatuto da Polícia Civil foi determinado pela Lei Complementar $n^{\circ} 03$ de 1974, estabelecendo a organização da Polícia Civil. Segue-se em 1978 o regulamento e a estrutura da Polícia Civil. $^{33}$

Segundo matéria exibida no jornal Paraná-online de 27 de novembro de 2003, a polícia civil contava com 3.100 policiais, entre delegados, investigadores e escrivães, para atender uma população de mais de nove milhões e meio de habitantes, que seria o estado com um todo, e que na década de 80 , o efetivo era de 2.900 homens e o número de habitantes era de sete milhões e meio de habitantes do estado do Paraná. ${ }^{34}$

Poderíamos colocar o número atual de delegados e agentes da polícia civil, mas, não vamos trabalhar com esses números, pois,

\footnotetext{
${ }^{31}$ Idem.

${ }^{32}$ Idem.

${ }^{33}$ STRAUBE, Ernani Costa. Op. cit.

${ }^{34}$ Paraná-Online. Polícia Civil Faz 150 Anos. Em 27 de novembro de 2003.
} 
segundo a constituição, a qual ressaltamos anteriormente, as funções da polícia civil são "funções de polícia judiciária e a apuração de infrações penais, exceto as militares", partindo para um viés mais investigativo, com apreensão de material ilegal e infratores. Vamos somente pontuar onde estão localizadas as delegacias da polícia civil (MAPA 1), pois estas servem de apoio à polícia ostensiva e à preservação da ordem pública, porém os agentes da polícia civil são voltados mais para função judiciária e não efetivamente com o executivo como o policial militar, que ao deter um indivíduo em flagrante encaminha o mesmo a delegacia mais próxima para ser indiciado juridicamente pelos seus atos e detido ser for necessário, ato este interpretado pelo delegado, agente da polícia civil, que está, em horário normal de trabalho ou de plantão, no referido distrito policial (delegacia).

Após a explanação das funções e da história das referidas instituições de segurança pública por nós elencadas para análise, e nossas razões para focar a quantidade de agentes que prestam o policiamento ostensivo e a realizam a preservação da ordem pública. Temos que detalhar mais um pouco os nossos motivos, por que policiamento ostensivo? A palavra ostensivo, adjetivo da palavra ostensível (adj $m+f$;lat ostensu $+i+v e l)$ que significa: Que se pode mostrar; Próprio para ser visto; Evidente, patente. ${ }^{35}$ Assim sendo, Policiamento ostensivo é policiamento preventivo, seja pelo uso de uniformes, seja pelo uso de viaturas caracterizadas ou até mesmo utilização de distintivos que colocam os agentes de segurança em evidência. Tendo por objetivo maior esta visibilidade de acarretar sensação de segurança e desestimular a realização de uma infração ou crime. Como coloca Foucault, que:

O exercício da disciplina supõe um dispositivo que obrigue pelo jogo do olhar, um aparelho onde as técnicas que permitem ver induzam a efeitos

35 MICHAELES. Moderno Dicionário da Língua Portuguesa. Editora Melhoramentos Ltda. 2007. 
de poder, e onde, os meios de coerção tornem claramente visíveis aqueles sobre quem se aplicam. ${ }^{36}$

Nesta linha de visibilidade, Foucault ressalta ainda que:

O acampamento é o diagrama de um poder que age pelo efeito de uma visibilidade geral. Durante muito tempo encontramos no urbanismo, na construção das cidades operárias, dos hospitais, dos asilos, das prisões, das casas de educação, esse modelo do acampamento ou pelo menos o princípio que o sustenta: o encaixamento espacial das vigilâncias hierarquizadas. Princípio do "encastramento". ${ }^{37}$

Nesta linha temos o estudo do Coronel Roberson Luiz Bondaruk, denominado A Prevenção do Crime Através do Desenho Urbano, no qual este ressalta a importância da visibilidade, ao colocar que grades são melhores que muros, pois a visibilidade do local coíbe ações dos delinqüentes, conforme sua tese e palestra ministrada para a ADESG turma 2008. ${ }^{38}$

Mas a forma das construções ou mesmo a disposição para coibir o crime já foram muito bem estudadas por Bondaruk em sua tese, não sendo esta nossa intenção nesta pesquisa.

Vamos nos pautar mais na Polícia Militar do Paraná que atua no município de Curitiba com o policiamento de área.

${ }^{36}$ FOUCAULT, Michel. Op. cit.

${ }^{37}$ Ibidem.

38 BONDARUK, Roberson Luiz. A Prevenção do Crime Através do Desenho Urbano. Curitiba: Editora do autor, 2007. 
Revista Vernáculo, n. 17 e 18, 2006

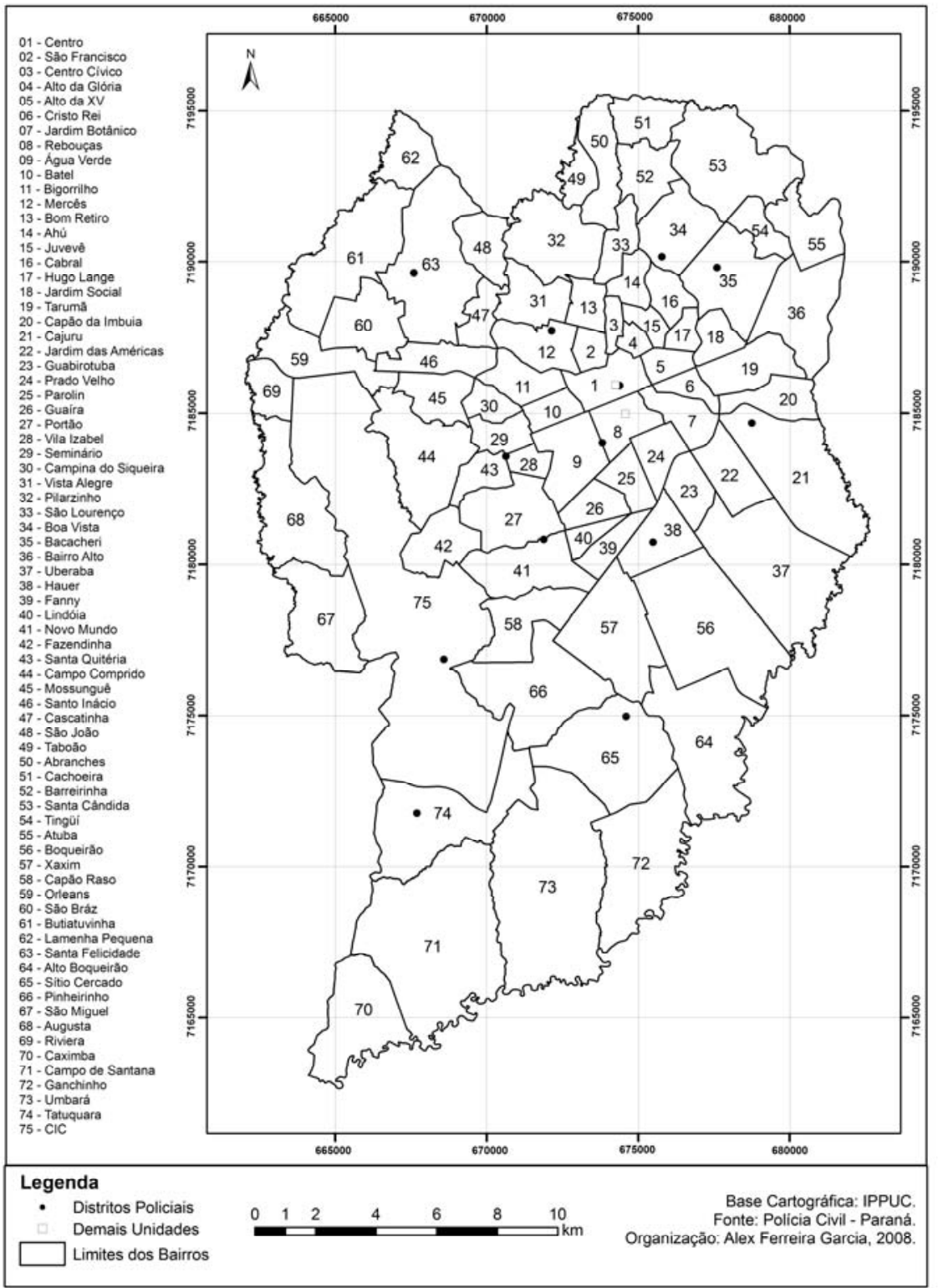

Mapa 01 - LOCALIZAÇÃO DOS DISTRITOS POLICIAIS DA POLÍCIA CIVIL EM CURITIBA. 
Atualmente o Comando de Policiamento da Capital conta com 3.672 policiais para realizar o policiamento ostensivo, porém, esta deveria ter 5991 policiais como previsto pela própria corporação, tendo assim uma defasagem de 2319 policiais. Tal defasagem ocorre pela saída de policias, por diversos motivos que não vem ao caso ser analisadas aqui, e nem possuímos tais dados, mas elencamos um, aposentadoria. Podemos analisar estes dados conforme gráfico (GRÁFICO 01) e notamos que a defasagem quase chega a quarenta por cento do efetivo $(38,7 \%)$.

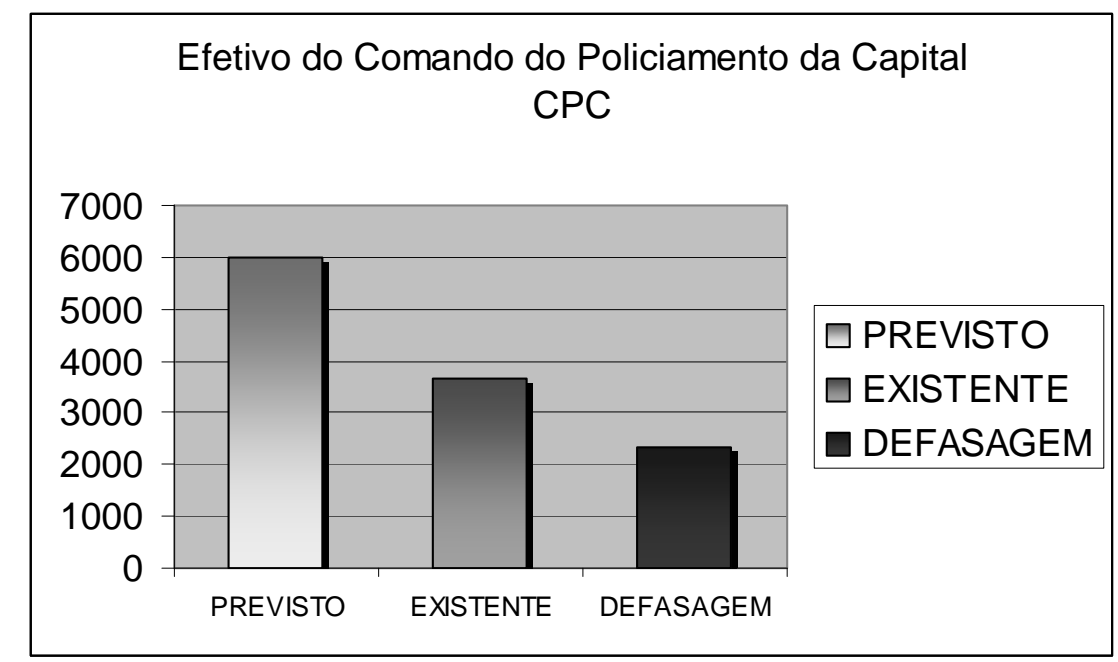

GRAFICO 01 - EFETIVO DE POLICIAIS MILITARES QUE CONSTA NO CPC Fonte: Comando do Policiamento da Capital.

Porém, para melhor análise, temos que relativizar os dados, levando em conta a área de atuação destes policiais e qual a clientela que atendem, para tal, temos que colocar quais as áreas de ação dos referidos batalhões que realizam o policiamento ostensivo na capital. Para realizar esta ação, elaboramos um mapa com as companhias de cada batalhão e os bairros que elas atuam (MAPA 2). E realizamos um paralelo com a população perante dados do censo de 2000 (o mais 
recente encontrado a disposição) e tabulados pelo IPPUC (Instituto de Pesquisa e Planejamento Urbano de Curitiba).

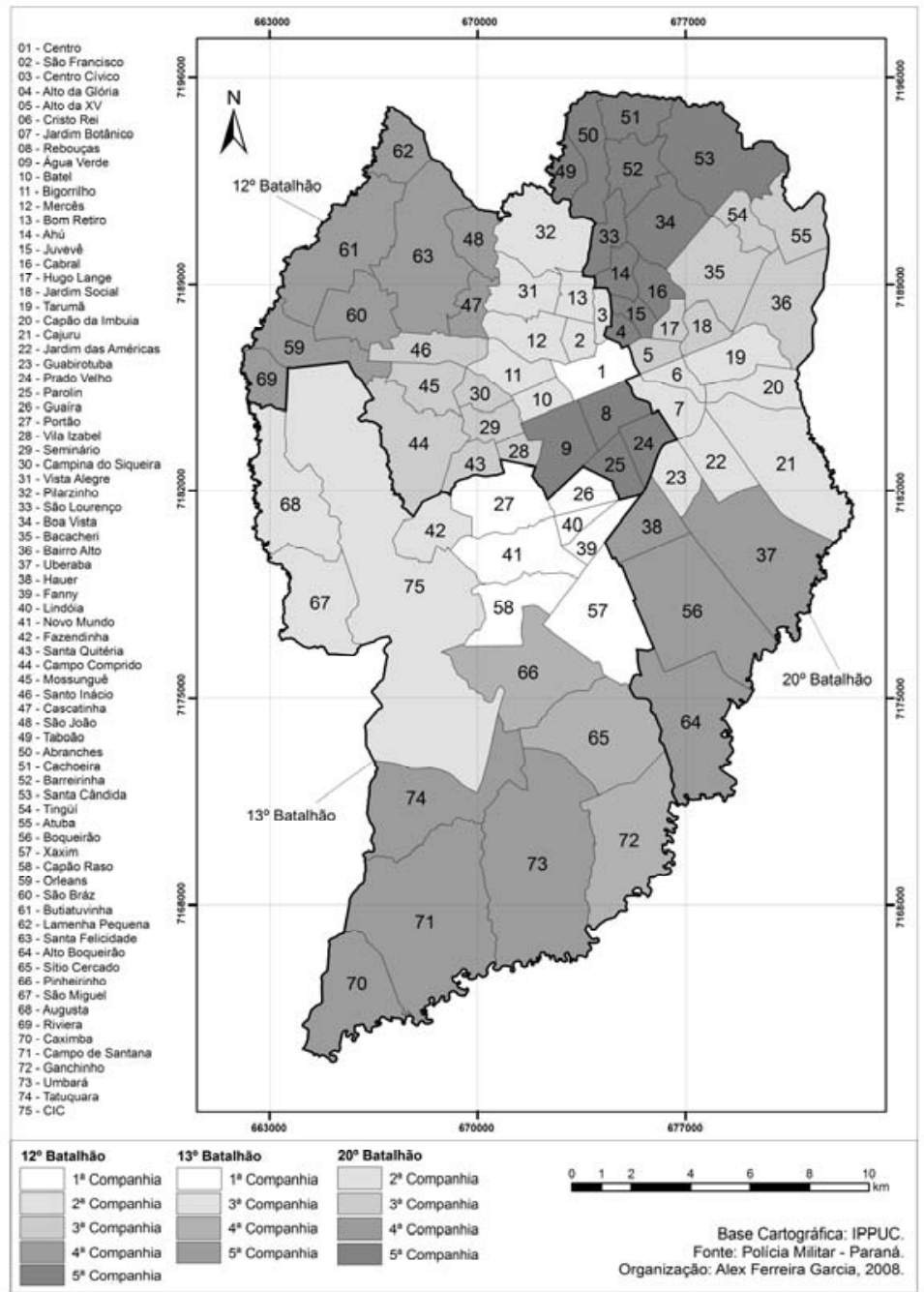

MAPA 2 - BATALHÕES E COMPANHIAS DA POLÍCIA MILITAR DO PARANÁ EM CURITIBA, NO ANO DE 2008.

Gerando após a análise dos dados a tabela: 
Revista Vernáculo, n. 17 e 18, 2006

\begin{tabular}{|c|c|c|c|c|c|}
\hline \multicolumn{2}{|l|}{$12^{\circ}$ Batalhão } & \multicolumn{2}{|c|}{$13^{\circ}$ Batalhão } & \multicolumn{2}{|c|}{$20^{\circ}$ Batalhão } \\
\hline Bairros & Hab & Bairros & Hab & Bairros & Hab \\
\hline Centro & 32623 & Augusta & 3617 & Abranches & 11165 \\
\hline Campina do Siqueira & 7108 & Campo de Santana & 7335 & Ahu & 11148 \\
\hline Campo Comprido & 21638 & Capão Raso & 34376 & Alto Boqueirão & 51155 \\
\hline Mossunguê & 5628 & Caximba & 2475 & Alto da Glória & 5588 \\
\hline Santo Inácio & 6037 & $\mathrm{CIC}$ & 157461 & Alto da XV & 8683 \\
\hline Seminário & 7395 & Fanny & 7866 & Atuba & 12632 \\
\hline Vila Izabel & 10949 & Fazendinha & 26122 & Bacacheri & 23106 \\
\hline Água Verde & 49866 & Ganchinho & 7325 & Bairro Alto & 42033 \\
\hline Parolin & 11982 & Guaíra & 14268 & Barreirinha & 17021 \\
\hline Prado Velho & 7084 & Lindóia & 8343 & Boa Vista & 29391 \\
\hline Rebouças & 15618 & Novo Mundo & 42999 & Boqueirão & 68495 \\
\hline Batel & 11778 & Pinheirinho & 49689 & Cabral & 11720 \\
\hline Bigorrilho & 27127 & Portão & 40735 & Cachoeira & 7738 \\
\hline Bom Retiro & 5633 & São Miguel & 4911 & Cajuru & 89784 \\
\hline Centro Cívico & 4767 & Sítio Cercado & 102410 & Capão da Imbuia & 20976 \\
\hline Mercês & 14089 & Tatuquara & 36339 & Cristo Rei & 13325 \\
\hline Pilarzinho & 27907 & Umbará & 14595 & Guabirotuba & 10678 \\
\hline São Francisco & 6435 & Xaxim & 54691 & Hauer & 13851 \\
\hline Vista Alegre & 9930 & & & Hugo Lange & 3167 \\
\hline Butiatuvinha & 10759 & & & Jardim Botânico & 6153 \\
\hline Cascatinha & 2061 & & & $\begin{array}{l}\text { Jardim das } \\
\text { Américas }\end{array}$ & 13966 \\
\hline Lamenha Pequena & 701 & & & Jardim Social & 6085 \\
\hline Orleans & 7260 & & & Juveve & 11281 \\
\hline Riviera & 203 & & & Santa Candida & 27870 \\
\hline Santa Felicidade & 25209 & & & São Lourenço & 5556 \\
\hline São Brás & 23119 & & & Taboão & 2668 \\
\hline \multirow[t]{3}{*}{ São João } & 2950 & & & Tarumã & 7045 \\
\hline & & & & Tingui & 11564 \\
\hline & & & & Uberaba & 60338 \\
\hline TOTAL & 355856 & TOTAL & 615557 & TOTAL & 604182 \\
\hline
\end{tabular}

TABELA 1 - POPULAÇÃO DOS BAIRROS DE CURITIBA

Fonte: IPPUC/Banco de Dados com Base no censo 2000 IBGE. 
Com base na referida tabela anteriormente citada (TABELA 1), realizamos a distribuição espacial deste, gerando um mapa que serviu de base para nossa análise (MAPA 3), mostrando o como está distribuída a polícia militar do estado do Paraná, nos batalhões de área na cidade de Curitiba.

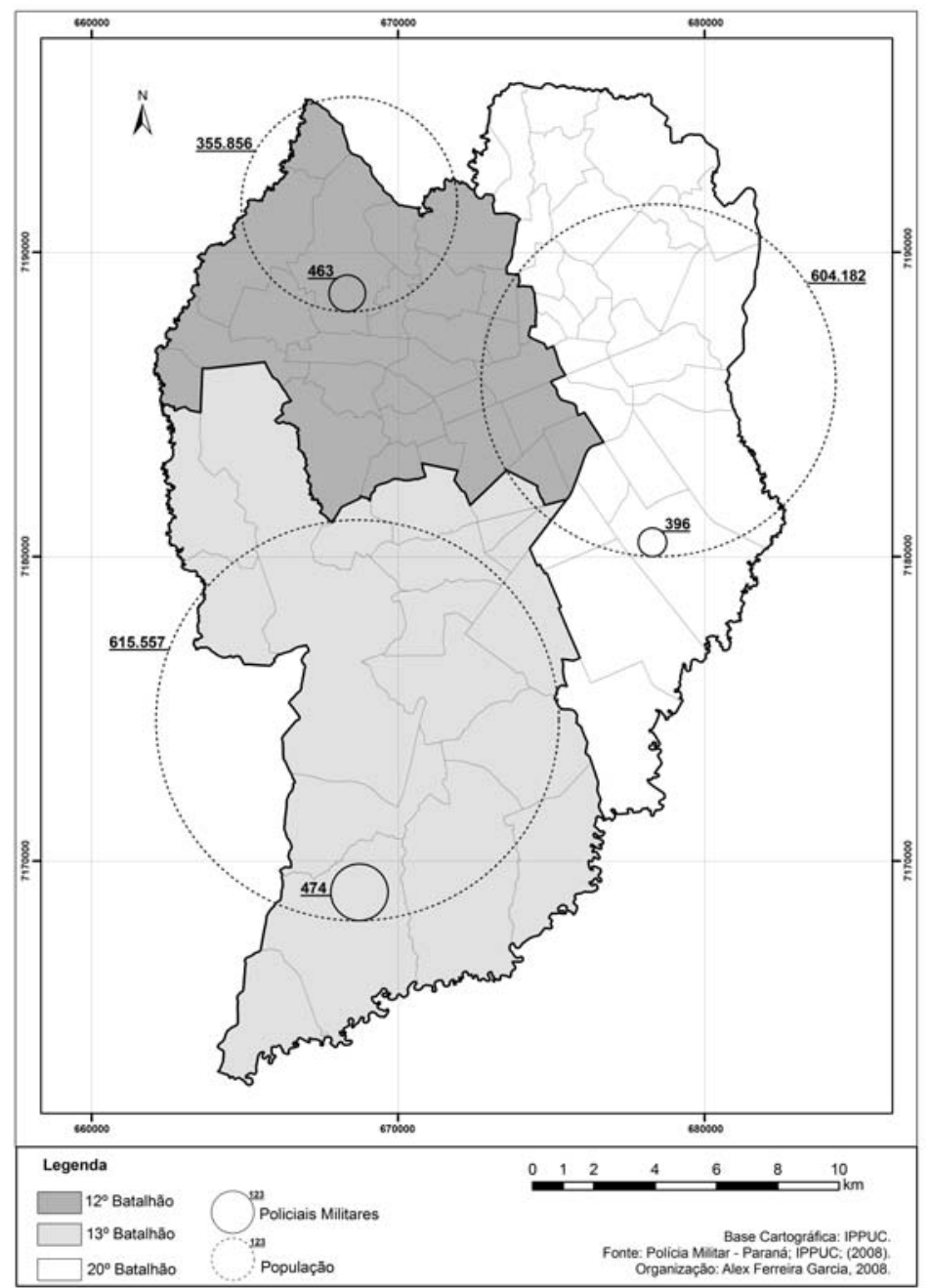

MAPA 3 - POPULAÇ̃̃O NAS ÁREAS DOS BATALHÕES POLÍCIA MILITAR DO PARANÁ EM CURITIBA E EFETIVO DOS REFERIDOS BATALHÕES. 
Após visualizar a distribuição, passamos para uma análise quantitativa, onde dividimos a quantidade da população de cada batalhão pela quantidade de agentes da polícia militar disponíveis para propiciar segurança para estes, não levando em conta o turno de trabalho, pois estes não trabalham todos ao mesmo tempo, tendo escalas de trabalho, e como não dispúnhamos deste dado, faremos a análise hipotética de que todos trabalham todos os dias, ficando assim: 768 habitantes para cada policial do $12^{\circ}$ Batalhão, 1.525 habitantes para cada policial do $20^{\circ}$ Batalhão e 1.293 habitantes para cada policial do $13^{\circ}$ Batalhão (TABELA 2).

\begin{tabular}{|c|c|c|c|}
\hline & $12^{\circ}$ Batalhão & $20^{\circ}$ Batalhão & $13^{\circ}$ Batalhão \\
\hline População da área do batalhão & 355.856 & 604.182 & 615.557 \\
\hline Quantidade de Policiais & 463 & 396 & 476 \\
\hline $\begin{array}{c}\text { Relação Habitantes por } \\
\text { Policial } \\
\end{array}$ & 768,587473 & 1525,712121 & 1293,186975 \\
\hline
\end{tabular}

Fonte: Polícia Militar do Paraná.

Para obtermos um bom parâmetro, fizemos a análise histórica desta relação, tendo como base, a criação da Polícia Militar do Paraná, no ano de 1854, sendo que nesta ocasião a corporação contava com 67 membros e a população da cidade de Curitiba era de 20.629 habitantes, o que corresponde a um total de 307 habitantes para cada membro da Polícia Militar na época. ${ }^{39}$ Mas, alguns podem dizer que essa quantidade de soldados correspondia ao Estado como um todo, assim, tivemos que computar a população de toda a "marinha" (Litoral) da época, que era de 19.442 habitantes, temos

${ }^{39}$ VASCONCELLOS, Zacarias de Góes e. Op. cit. 
assim um total de 40071 habitantes. ${ }^{40}$ Calculamos assim a relação agente de segurança e a quantidade populacional, temos uma relação de 598 habitantes por agente de segurança pública da Polícia Militar do Paraná.

Temos que citar ainda que existem 165 agentes em formação, ou seja, policiais em treinamento que adentraram nos quadros da instituição ainda este ano, vindo a amenizar a falta de efetivo.

Com base nestes números, encontramos uma grande defasagem na relação agente de segurança/habitantes existente em Curitiba, porque mesmo os melhores números, que são do $12^{\circ}$ Batalhão da Polícia Militar, ficam muito aquém em relação aos números do início da corporação, em 1854.

Assim, utilizando-nos do método hipotético-dedutivo, nos deparamos com um problema, a quantidade de agentes de segurança pública por habitante é muito pequena em relação à quantidade que já obteve em meados do século XIX. Para tal, utilizamos o método de hipótese de solução para este fato.

Poderíamos deixar esta relação menor caso a sociedade esteja em um patamar de crime muito baixo, justificando a diminuição da quantidade de agentes pelo não uso deles. Porém, esta hipótese cai por solo ao fazermos uma análise simples da quantidade de homicídios em Curitiba. Verificou-se que na capital paranaense houve uma substancial elevação na taxa média de homicídios entre 1986-88 e 1996-98, saindo de 14,89 para 25,98 por 100.000 habitantes, significando um crescimento de $74,30 \%$ na taxa média de homicídios no período analisado, que foi mais de dez vezes superior ao apresentado pelo país, $7,18 \%{ }^{41}$

Perante os dados, teríamos assim que utilizarmos a hipótese de aumento do efetivo, podendo alguns apontar ainda que não seria

\footnotetext{
${ }^{40}$ Idem.

${ }^{41}$ TEIXEIRA, Evandro Camargos. Estimando o impacto econômico da violência: custos da criminalidade em Curitiba. Dissertação (mestrado) - Programa de PósGraduação em Desenvolvimento Econômico, UFPR. Curitiba, 2005.
} 
necessário perante a utilização de tecnologias novas que suprem a demanda por policiamento ostensível, sendo esta o emprego de câmeras para monitoramento, como ocorre em parte do centro de Curitiba. No entanto, sabemos que a presença humana não pode ser descartada por completo na ação de coibir o crime perante policiamento ostensível, vindo o sistema de monitoramento via câmera contribuir para o policiamento e não substituir.

Aumentar o efetivo implicaria em mais gastos com segurança pública. Os gastos com segurança pública em Curitiba, no ano de 2001, foram de $\mathrm{R} \$ 155.250 .706,36$; composto este por $\mathrm{R} \$$ 137.208.706,36 (88,38\% do total) do governo do estado do Paraná através da SESP e R\$ 18.042.000,00 (11,62\% do total) da alça da esfera municipal frente à Prefeitura Municipal de Curitiba. Já os gastos com a custódia e reintegração social de presos em Curitiba foram estimados em $\mathrm{R} \$$ 8.662.555,80 no ano de 2001, mesmo sendo uma área com problemas e falta de mais vagas para sanar super lotação. Os gastos com o judiciário também não são pequenos, sendo na esfera de R\$7.197.312,00; estes gastos são compostos com salários de juízes, promotores e advogados da defensoria pública. ${ }^{42}$

Os gastos com saúde em decorrência da violência são estimados através dos dados coletados junto ao Movimento de Autorização de Internação Hospitalar (MAIH) e ao Sistema de Informação Ambulatorial (SAI) do Ministério da Saúde. O gasto total com saúde decorrente da violência em Curitiba no ano de 2002 foi de $\mathrm{R} \$$ 2.655.713,37. Deste valor estimado, $\mathrm{R} \$ 2.281 .471,75(85,91 \%)$ tiveram como origem os atendimentos de emergência e ambulatoriais do SAI. O restante, R $\$ 374.241,62$ (14,09\%), correspondeu aos gastos com internação hospitalar das vítimas da violência em Curitiba. Os gastos com seguros e equipamentos de segurança foram estimados através da Pesquisa de Orçamento Familiar do IBGE no período de julho de 2002 a junho de $2003 .^{43}$

Para Milton Santos:

${ }^{42}$ TEIXEIRA, Evandro Camargos. Op. cit.

${ }^{43}$ Idem. 
O emprego aumentado e a massa salarial acrescida representaria uma fase para a criação de novas atividades, que, por sua vez, atrairiam outras mais... ...O circulo vicioso se transformaria em círculo virtuoso, em espiral ascendente ou numa bola de neve, e haveria crescimento econômico. Essa mudança da ótica no tratamento dos problemas sociais, de modo a incorporar o dado geográfico, seria eficaz, tanto do ponto de vista social, como do econômico e mesmo político. ${ }^{44}$

Quando colocamos a hipótese de aumentar a quantidade do efetivo dos batalhões, sabemos que haverá um aumento dos gastos do estado para tal, porém, este também teria um retorno, já que o agente de segurança pública é um cidadão que estará usufruindo do serviço prestado por ele mesmo (segurança pública), além de empregar seus rendimentos no comércio local, que gera uma arrecadação maior de impostos, que por sua vez paga o salário deste agente público, sendo um processo retroalimentado.

Outra hipótese de solução do problema é a de dar responsabilidade de policiamento ostensível a guarda municipal, modificando a lei maior da nação (a Constituição de 1988) e a lei municipal que rege a guarda municipal de Curitiba (Lei Ordinária $n^{\circ}$ 6867/1986) mudando as atribuições da guarda municipal. Porém, esta já está incumbida de grandes responsabilidades, tais como guardar todas as escolas municipais e os espaços públicos contra vandalismo ou roubo. Mas se esta for incumbida de realizar policiamento ostensível visando dar segurança a todo o cidadão, creio eu, que seu efetivo se tornará insuficiente para tal, tendo que haver acréscimo deste para cumprir tal função.

Podemos sofrer críticas frente à evolução dos recursos para vigilância, pois contamos com câmeras e patrulhamento com viaturas, ou até mesmo helicópteros, mas não temos informações sobre estes recursos, e se tivéssemos, iríamos espacializar estes e ver qual a população que este atende, para melhor analisar. Porém, mesmo com emprego de câmeras, necessitamos de policiais deter os inflares em

44 SANTOS, Milton. O Espaço do Cidadão. 7 ed. São Paulo: Editora da Universidade de São Paulo, 2007. p. 145. 
pleno delito, assim, estas não substitui totalmente o policiamento ostensível. Podemos fazer uma analogia com a época de Zacarias Góes de Vasconcellos, que a maior tecnologia de transporte da época, eles também possuíam, que era cavalos, ficando cada uma adaptado a seu tempo e conforme as condições que tinham, frente a recursos a ser empregados, ficando os dias atuais, quanto a relação numérica habitantes/agentes de segurança pública para o patrulhamento ostensível, muito defasada atualmente, século XXI, em relação a meados do século XIX, relativamente e proporcionalmente colocados, e não encontramos, perante o método de falseamento das hipóteses, uma resposta plausível para justificar esta defasagem, pois o investimento em segurança pública, perante diversos estudos apontados neste trabalho, torna-se economicamente mais viável, isso sem colocarmos o valor das vidas poupadas, que creio eu, não ser possível mensurar o valor de uma vida humana.

Como definir uma solução para nosso problema, a segurança pública? Não podemos tratar a segurança pública como um problema e sim uma solução para um problema, a criminalidade, que vimos ser indissociável da sociedade.

Frente a realizar considerações finais em um trabalho complexo que chegar em uma conclusão é algo muito difícil, baseamo-nos no trabalho de André Oliveira Ferreira Loureiro (Mestre em Economia - Universidade Federal do Ceará) e José Raimundo de A. Carvalho Jr. (Doutor em Economia - Pennsylvania State University, EUA) denominado "O Impacto dos Gastos Públicos sobre a Criminalidade no Brasil" que:

Utilizando novos dados da SENASP (Secretaria Nacional de Segurança Pública)... ...tem por objetivo estimar o impacto dos gastos em segurança pública e assistência social sobre criminalidade nos estados brasileiros no período entre 2001 e 2003 . $^{45}$

${ }^{45}$ LOUREIRO, André Oliveira Ferreira; JUNIOR, José Raimundo de Araújo Carvalho. O Impacto dos Gastos Públicos sobre a Criminalidade no Brasil. p. 1. Disponível 
Para esses autores, os resultados obtidos na pesquisa deles evidenciaram que não existe um poder de dissuasão consistente de medidas de repressão, no caso, gastos em segurança pública, sobre o crime no Brasil, no período analisado (entre 2001 e 2003), mesmo quando o problema de endogeneidade é levado em consideração, com exceção de homicídios e das estimativas alternativas, onde a repressão pública de curto prazo reduz essa modalidade de crime. Esse resultado estaria de acordo com argumento de autores que afirmam que o poder dissuasório de variáveis de repressão, se existente, é limitado. ${ }^{46}$

Como consideramos que a vida humana não tem preço e perder um ser humano em nossa sociedade é uma perda impagável, consideramos que os números frente a diminuição de homicídios já é bastante significativo.

Quanto a análise de investimento, frente à outra pesquisa apontada anteriormente, e esta feita por Evandro Camargos Teixeira $^{47}$, mostra que os gastos com ambulatórios ou mesmo prejuízos frente ao crime são muito grande, tendo que haver uma melhor investimento no setor segurança pública, que no nosso caso de pesquisa seria em agentes de segurança, frente ao policiamento ostensivo para coibir o crime, e, dependendo do decorrer do processo, investimentos no judiciário e no sistema carcerário, que "se propõe a recuperar e reeducar os presos e prepará-los para retornar à sociedade e se tornarem produtivos para que não reincidam em práticas delituosas". 48 Sendo estes temas (Judiciário e Sistema Carcerário) amplos e cada um deles mereceria uma análise mais detalhada e estudos aprofundados, o que não é nosso caso.

http://www.bnb.gov.br/content/aplicacao/Eventos/ForumBNB2007/docs/o-impactodos-gastos.pdf.

${ }^{46}$ LOUREIRO, André Oliveira Ferreira; JUNIOR, José Raimundo de Araújo Carvalho. Op. cit.

${ }^{47}$ TEIXEIRA, Evandro Camargos. Op. cit.

48 NETO, Luiz Guedes da Luz. Sistema Carcerário Brasileiro. Disponível em http://www.factum.com.br/artigos/039.htm. 
Juntamente com gastos em segurança devem ser empregados gastos em assistência social, como mostra a pesquisa de André Oliveira Ferreira Loureiro e José Raimundo de A. Carvalho Jr, que encontraram:

Com relação aos gastos públicos em assistência social, na maioria das estimativas e das categorias de crime analisadas, essa variável apresentou um efeito negativo sobre a criminalidade. Essa relação pareceu ser robusta e nos levou a conclusão que este tipo de gasto é um importante fator para a redução do crime. Esse efeito estaria de acordo com os resultados obtidos para as variáveis socioeconômicas, visto que o gasto em assistência social afetaria esses fatores, direta ou indiretamente. ${ }^{49}$

Não estamos com este trabalho pedindo maior investimento em segurança pública, somente o proporcional a meados do século XIX. Já que regredimos em muito na relação habitante/policial militar da instituição Polícia Militar do Paraná.

\section{BIBLIOGRAFIA}

BRASIL, Constituição(1988). Constituição da República Federativa do Brasil: Texto constitucional promulgado em 5 de outubro de 1988, com as alterações adotadas pelas Emendas Constitucionais $n^{0} \mathrm{~s} 1 / 92$ a 56/2007 e pelas Emendas Constitucionais de Revisão nº 1 a 6/94. Brasília: Senado Federal. Disponível em: http://www.planalto.gov.br/ccivil_03/Constituicao/Constitui\%C3\%A 7ao.htm. Acessado em: 10 de maio de 2008.

BONDARUK, Roberson Luiz. A Prevenção do Crime Através do Desenho Urbano. Curitiba: Editora do autor, 2007.

CORRÊA, Sérgio Luís de Castro Mendes. O Conceito de Crime em Durkheim. Disponível em:

49 LOUREIRO, André Oliveira Ferreira; JUNIOR, José Raimundo de Araújo Carvalho. Op. cit. p. 20. 
http://www.escola.agu.gov.br/revista/Ano_VI_fevereiro_2006/conceit o\%20de\%20crime.pdf. Acessado em: 01/10/2008.

DELAZARI, Luiz Fernando Ferreira. PROJETO MAPA DO CRIME - PLANEJAMENTO E SEGURANÇA. Secretário de Estado da Segurança Pública do Paraná. São Paulo, 17 De Julho De 2008. Disponível

em:

http://www.geobr.com.br/conteudo/arquivos/Congresso $\% 20$ EXPO $\% 2$ 0GPS/Sala $\% 206 /$ Geotecnologias $\% 20$ combatendo $\% 20$ o $\% 20$ crime $\% 2$ 0-\%20Luis\%20Fernando\%20Delazari.ppt

Acessado em: 10/10/2008.

FOUCAULT, Michel. Vigiar e Punir: História da Violência nas Prisões. Rio de Janeiro, Editor Vozes, 1975.

GOMES, Carlos Alberto da Costa. Espaço Urbano e Criminalidade: Uma Breve Visão do Problema. Revista de Desenvolvimento Econômico, Salvador, v. 8, $\mathrm{n}^{\circ}$ 1, 2005. Disponível na Internet na. URL:

http://www.revistas.unifacs.br/index.php/rde/article/download/97/101 . Acessado em: 20/08/2008

IBGE, Instituto Brasileiro de Geografia e Estatística. Censo 2000. Disponível em: http://www.ibge.gov.br/home/ Acessado em: 15/10/2008.

LAKATOS, Eva Maria; MARCONI, Marina de Andrade.

Fundamentos de metodologia científica. $3^{\mathrm{a}}$ ed. São Paulo: Atlas, 1991.

LOUREIRO, André Oliveira Ferreira; JUNIOR, José Raimundo de Araújo Carvalho. O Impacto dos Gastos Públicos sobre a Criminalidade no Brasil. Disponível em: http://www.bnb.gov.br/content/aplicacao/Eventos/ForumBNB2007/d ocs/o-impacto-dos-gastos.pdf Acessado em: 20/08/2008.

LUZ NETO, Luiz Guedes da. Sistema Carcerário Brasileiro. Disponível em: http://www.factum.com.br/artigos/039.htm. Acessado em: 29/11/2008.

MICHAELES. Moderno Dicionário da Língua Portuguesa. Editora Melhoramentos Ltda. 2007. 
PARANÁ-ONLINE. Grande Curitiba Registra 24 Homicídios. Disponível em:

online.com.br/editoria/policia/news/339184/. http://www.parana01/12/2008.

PARANÁ-ONLINE. Crimes na CIC e no Hauer. Disponível em: http://www.parana-online.com.br/editoria/policia/news/338669/.

Acessado em: 01/12/2008.

PARANÁ-ONLINE. Polícia Civil Faz 150 Anos. Em 27 de novembro de 2003.

Polícia Militar do Paraná. Histórico. Disponível em: http://www.pm.pr.gov.br/modules/conteudo/conteudo.php?conteudo= 1 Acessado em: 12/10/2008.

POPPER, K. A lógica da Investigação Cientifica. São Paulo: Abril Cultural,1980.

QUENTAL, Nunes. A organização espacial do território como contributo para a sustentabilidade. Disponível em: $\mathrm{http}: / /$ conferencias.iscte.pt/viewpaper.php?id $=58 \& \mathrm{cf}=3$. Acessado em: 02/05/2008

RIBEIRO, Orlando. Paisagens, Regiões e Organização do Espaço. Finisterra, XXXVI, 72, p. 27-35, 2001.

SANTOS, Milton. $O$ Espaço do Cidadão. 7 ed. São Paulo: Editora da Universidade de São Paulo, 2007.

SOARES, Luiz Eduardo. Notas sobre a Problemática da Segurança Pública. Disponível em:

http://www.ipea.gov.br/sites/000/2/publicacoes/bpsociais/bps_02/ens aio3_notas.pdf. Acessado em: 20/10/2008

SPL, Sistema de Proposições Legislativas. Leis Municipais: Acessado em: http://domino.cmc.pr.gov.br/contlei.nsf/\$\$Search?OpenForm. Disponível em 10/10/2008.

SPL, Sistema de Proposições Legislativas. Guarda Municipal tem trabalho destacado. Em 02 de outubro de 2007. Disponível em: http://www.cmc.pr.gov.br/ass_det.php?not=9963. Acessado em $03 / 10 / 2008$ 
STRAUBE, Ernani Costa. "Histórico" da polícia civil do Paraná, Disponível no site da Polícia Civil http://www.policiacivil.pr.gov.br/modules/conteudo/conteudo.php?co nteudo=1. Acessado em 29/10/2008.

TEIXEIRA, Ricardo Rodrigues. Três fórmulas para compreender " $\mathrm{O}$ suicídio" de Durkheim. Disponível em: http://www.interface.org.br/revista11/espaco1.pdf. Acessado em 10/05/2008.

TEIXEIRA, Evandro Camargos. Estimando o impacto econômico da violência: custos da criminalidade em Curitiba. Dissertação (mestrado). Programa de Pós-Graduação em Desenvolvimento Econômico - UFPR. Curitiba, 2005.

VASCONCELLOS, Zacarias de Góes e. Relatorio do presidente da provincia do Paraná, o conselheiro Zacarias de Góes e Vasconcellos, na abertura da Assemblea Legislativa Provincial em 15 de julho de 1854. Curityba, Typ. Paranaense de Candido Martins Lopes, 1854. Disponível em: http://brazil.crl.edu/bsd/bsd/614/index.html. Acessado em: 23/09/2008. 